\title{
Physical properties of Pseudomonas and Rhizomucor miehei lipase-catalyzed transesterified blends of palm stearin:palm kernel olein
}

\begin{abstract}
The physical properties of Pseudomonas and Rhizomucor miehei lipase-catalyzed transesterified blends of palm stearin:palm kernel olein (PS:PKO), ranging from $40 \%$ palm stearin to $80 \%$ palm stearin in $10 \%$ increments, were analyzed for their slip melting points (SMP), solid fat content (SFC), melting thermograms, and polymorphic forms. The Pseudomonas lipase caused a greater decrease in SMP $\left(15^{\circ} \mathrm{C}\right)$ in the PS:PKO (40:60) blend than the R. miehei lipase $\left(10.5^{\circ} \mathrm{C}\right)$. Generally, all transesterified blends had lower SMP than their unreacted blends. Pseudomonas lipase-catalyzed blends at 40:60 and 50:50 ratio also showed complete melting at $37^{\circ} \mathrm{C}$ and $40^{\circ} \mathrm{C}$, respectively, whereas for the R. miehei lipasecatalyzed 40:60 blend, a residual SFC of $3.9 \%$ was observed at $40^{\circ} \mathrm{C}$. Randomization of fatty acids by Pseudomonas lipase also led to a greater decrease in SFC than the rearrangement of fatty acids by R. miehei lipase. Differential scanning calorimetry results confirmed this observation. Pseudomonas lipase also successfully changed the polymorphic forms of the unreacted blends from a predominantly 6 form to that of an exclusively $6 \mathrm{Nj}$ jorm. Both $\mathrm{b}$ and $\mathrm{bNj}$ forms existed in the R. miehei lipase-catalyzed reaction blends, with bNipeing the dominant form.
\end{abstract}

Keyword: DSC; Lipase; Palm kernel olein; Palm stearin; Polymorphic forms; Pseudomonas; Rhizomucor miehei; Slip melting points; Solid fat content; Table margarines; Transesterification 